\title{
Production and Characterization of High Value Prebiotics From Biorefinery-Relevant Feedstocks
}

\author{
Kalavathy Rajan ${ }^{1 \times \dagger}$, Doris H. D'Souza ${ }^{2}$, Keonhee Kim ${ }^{1}$, Joseph Moon Choi ${ }^{2}$, Thomas Elder ${ }^{3}$, \\ Danielle Julie Carrier ${ }^{4}$ and Nicole Labbé ${ }^{1,5 *}$
}

OPEN ACCESS

Edited by:

Debarati Paul,

Amity University, India

Reviewed by:

Wen Wang,

Guangzhou Institute of Energy

Conversion (CAS), China

Wei Qi,

Guangzhou Institute of Energy

Conversion (CAS), China

*Correspondence:

Nicole Labbé nlabbe@utk.edu Kalavathy Rajan krajan@utk.edu

${ }^{+}$Present address: Kalavathy Rajan,

CRC - Material Science and Technology Unit, Knoxville, TN, United States

Specialty section: This article was submitted to Microbiotechnology,

a section of the journal

Frontiers in Microbiology

Received: 02 March 2021 Accepted: 06 April 2021

Published: 29 April 2021

Citation:

Rajan K, D'Souza DH, Kim KH, Choi JM, Elder T, Carrier DJ and Labbé N (2021) Production and

Characterization of High Value Prebiotics From Biorefinery-Relevant Feedstocks.

Front. Microbiol. 12:675314. doi: 10.3389/fmicb.2021.675314
${ }^{1}$ Center for Renewable Carbon, The University of Tennessee Institute of Agriculture, Knoxville, TN, United States, ${ }^{2}$ Department of Food Science, The University of Tennessee Institute of Agriculture, Knoxville, TN, United States, ${ }^{3}$ USDAForest Service, Southern Research Station, Auburn, AL, United States, ${ }^{4}$ Department of Biosystems Engineering and Soil Science, The University of Tennessee Institute of Agriculture, Knoxville, TN, United States, ${ }^{5}$ Department of Forestry, Wildlife and Fisheries, The University of Tennessee Institute of Agriculture, Knoxville, TN, United States

Hemicellulose, a structural polysaccharide and often underutilized co-product stream of biorefineries, could be used to produce prebiotic ingredients with novel functionalities. Since hot water pre-extraction is a cost-effective strategy for integrated biorefineries to partially fractionate hemicellulose and improve feedstock quality and performance for downstream operations, the approach was applied to process switchgrass (SG), hybrid poplar (HP), and southern pine (SP) biomass at $160^{\circ} \mathrm{C}$ for $60 \mathrm{~min}$. As a result, different hemicellulose-rich fractions were generated and the chemical characterization studies showed that they were composed of $76-91 \%$ of glucan, xylan, galactan, arabinan, and mannan oligosaccharides. The hot water extracts also contained minor concentrations of monomeric sugars $(\leq 18 \%)$, phenolic components $(\leq 1 \%)$, and other degradation products $(\leq 3 \%)$, but were tested for probiotic activity without any purification. When subjected to batch fermentations by individual cultures of Lactobacillus casei, Bifidobacterium bifidum, and Bacteroides fragilis, the hemicellulosic hydrolysates elicited varied responses. SG hydrolysates induced the highest cell count in L. casei at $8.6 \log _{10}$ cells $/ \mathrm{ml}$, whereas the highest cell counts for $B$. fragilis and $B$. bifidum were obtained with southern pine $\left(5.8 \log _{10} \mathrm{cells} / \mathrm{ml}\right)$ and HP hydrolysates $\left(6.4 \log _{10} \mathrm{cell} / \mathrm{ml}\right)$, respectively. The observed differences were attributed to the preferential consumption of mannooligosaccharides in SP hydrolysates by $B$. fragilis. Lactobacillus casei preferentially consumed xylooligosaccharides in the switchgrass and southern pine hydrolysates, whereas $B$. bifidum consumed galactose in the hybrid poplar hydrolysates. Thus, this study (1) reveals the potential to produce prebiotic ingredients from biorefinery-relevant lignocellulosic biomass, and (2) demonstrates how the chemical composition of hemicellulose-derived sources could regulate the viability and selective proliferation of probiotic microorganisms.

Keywords: Hemicellulosic oligosaccharides, hybrid poplar, switchgrass, southern pine, batch fermentation, Lactobacillus casei, Bifidobacterium bifidum, Bacteroides fragilis 


\section{INTRODUCTION}

Hemicellulose, a structural polysaccharide constituting 9-34\% of lignocellulosic biomass (Yadav et al., 2018), is often an undervalued and underutilized stream of biorefinery processes with untapped potential in platform chemicals, and food and cosmetic industries (Takkellapati et al., 2018; Lolou and Panayiotidis, 2019). The native structure of hemicellulose varies depending on the plant species, with the predominant forms in herbaceous, hardwood, and softwood biomass being arabinomethylglucuronoxylan, methylglucuronoxylan, and galactoglucomannan, respectively (Spiridon and Popa, 2008). Their unique structure and chemical composition create new opportunities for diversification and high-value nutraceutical applications such as prebiotics.

Prebiotics are indigestible oligosaccharides commonly produced from food sources such as chicory root, milk, and oats (Davani-Davari et al., 2019), and are known to promote the growth of beneficial probiotic microorganisms in the lower intestine of mammals. Hemicellulosic oligosaccharides (HOS) prepared from lignocellulosic biomass have also been reported to impart similar benefits. HOS, composed of galactoglucomannan and arabinoglucuronoxylan isolated from Norway spruce and birch wood, were reported to selectively induce the proliferation of Bifidobacteria and in turn improve the production of short chain fatty acids like butyric and propionic acids (La Rosa et al., 2019). Similarly, xylooligosaccharides produced from Miscanthus were reported to sustain the growth of Lactobacillus brevis, as well as promote the production of lactic and acetic acids (Hong et al., 2019). In vitro and in vivo studies have shown that supplementation with xylooligosaccharides could provide additional benefits, including reduction of inflammatory cell signaling pathways (Hansen et al., 2013) and improvement in gut barrier functions (Thiennimitr et al., 2018). Together, these physiological changes have been reported to mitigate obesity (Thiennimitr et al., 2018), colon cancer (Hsu et al., 2004), type-2 diabetes (Yang et al., 2015) and improve the overall immune response (Pham et al., 2018). Hence, investigating the prebiotic potential of HOS derived from renewable lignocellulosic feedstocks would pave way for achieving new health benefits as well as generate new revenue streams for biorefineries. Moreover, the demand for prebiotic ingredients is expected to reach 1.35 million tons by 2024 (Ahuja and Deb, 2017), therefore, complementing food sources with lignocellulosic feedstocks would make the prebiotic ingredient industry more sustainable.

Different biorefineries will utilize different regionally available lignocellulosic feedstocks, and for a sustainable year-round operation it may even be essential to switch between feedstocks (Baral et al., 2019). Hence, it is necessary to investigate the efficacy of prebiotics production from multiple sources. Hybrid poplar (HP) and switchgrass (SG) are dedicated energy crops, with field trials in the United States averaging a productivity of 15 ton ha $\mathrm{hr}^{-1} \mathrm{yr}^{-1}$ (Volk et al., 2018) and 10 ton $\mathrm{ha}^{-1} \mathrm{yr}^{-1}$ (Kim et al., 2020), respectively. These crops grow rapidly on a range of sites including marginal land and former industrial sites, providing numerous environmental benefits such as low carbon footprint, enhanced water and soil quality, as well as creating diverse landscapes that support biodiversity (Townsend et al., 2018). Complementing energy crops with regional feedstocks, such as southern pine (SP) whose net production in 2015 was 132 million wet tons in the Southern United States (Gray et al., 2018), would enhance the development of sustainable supply chains for various bioconversion platforms (Edmunds et al., 2018). Hence, these three biorefinery-relevant feedstocks were chosen for this study and to our knowledge, this is the first time they have been investigated for prebiotic production potential.

Of the different strategies employed to fractionate hemicellulose from lignocellulosic biomass, including alkaline (Geng et al., 2018), dilute acid (Rusanen et al., 2019), and hot water hydrolysis (Gallina et al., 2018), the use of hot water has dual advantages of improving the feedstock quality and performance for downstream conversion (Wells et al., 2020) and also requiring no chemical inputs (Kim et al., 2009). Hot water pretreatment reduces inorganic impurities and improves biomass combustion quality (Liu et al., 2018), as well as reduces biomass recalcitrance and enhances fermentable sugar production (Wells et al., 2020). Moreover, up to $95 \%$ of hemicellulose could be fractionated from lignocellulosic biomass using hot water extraction (HWE) at $160-170^{\circ} \mathrm{C}$, for $40-120 \mathrm{~min}$ (Krogell et al., 2013; Gallina et al., 2018). The liquid hydrolysates fractionated during HWE are enriched in HOS and could either be used directly or after partial purification for prebiotic applications (Chen et al., 2015). Since the source of HOS has been shown to have a significant effect on ensuing probiotic activity (Hong et al., 2019; La Rosa et al., 2019), it is essential to understand how the structure and compostion of HOS derived from different biorefinery-relevant feedstocks will impact both the quality and level of prebiotic production.

In this study, we conducted extensive characterization of HOS fractionated from SG, HP, and SP, and investigated their capability to sustain individual cultures of probiotic microorganisms. Probiotic bacteria belonging to Lactobacillus and Bifidobacterium genera are naturally found in the small and large intestine of humans (Ng et al., 2014), and hence, Lactobacillus casei and Bifidobacterium bifidum were selected as our test systems. Lactobacillus casei has been proven to proliferate in dairy products, xylo-oligosaccharides and fructooligosaccharides (Hill et al., 2018), whereas B. bifidum, a key member of infant gut microbiota $(\sim 10 \%)$, is known to grow in the mucosal barrier (Turroni et al., 2020) and to establish well in galacto- and fructo-oligosaccharides (Sims and Tannock, 2020). Both these bacteria have never been tested for their ability to ferment switchgrass, hybrid poplar, or southern pinederived HOS. In addition to using these well-established microorganisms, an emerging probiotic bacterium Bacteroides fragilis, which has exhibited the potential to utilize xylooligosaccharides, was evaluated in our study (La Rosa et al., 2019). The phylum Bacteroidetes have been reported to dominate the adult human gut by $26-32 \%$ and also aid in the fermentation of complex carbohydrates, proteins, and fats (Poeker et al., 2018), thereby promoting overall well-being. 
Hence, by investigating the efficacy of HOS fermentation by these selected probiotic bacteria, we could provide insights about how the structure and composition of HOS, isolated from different biorefinery-relevant lignocellulosic feedstocks, could affect their in vitro proliferation. Our long term goal is to establish HOS structure-function relationship and thereby, optimize the HWE of high-quality prebiotics from lignocellulosic feedstocks.

\section{MATERIALS AND METHODS}

\section{Biomass}

Pulp grade chips of debarked hybrid poplar (Populus deltoides $\times$ Populus trichocarpa) and southern pine (Pinus taeda L.) wood were obtained from the Center for Renewable Carbon (Knoxville, TN), and Auburn University (Auburn, AL), respectively. The average size of wood chips was $4 \mathrm{~cm}^{2}$ and $0.5 \mathrm{~cm}$ in thickness. Chopped stalks and leaves of switchgrass (Panicum virgatum L.) Alamo variety were obtained from Genera Energy LLC (Vonore, TN). The average particle size of the switchgrass biomass was $0.48 \mathrm{~cm}$. All biomass materials were reduced to a particle size of $0.43 \mathrm{~mm}$ (40-mesh) using a Thomas Wiley ${ }^{\circledR}$ mini-blade mill (Swedesboro, NJ) for chemical characterization purposes. The chemical composition of starting biomass materials is provided in Table 1 .

\section{Hot Water Extraction of Hemicellulosic Sugars}

Prior to hot water extraction, all biomass materials were pre-conditioned by first heating with water and then with $95 \%$ ethanol, at $100^{\circ} \mathrm{C}$ for $60 \mathrm{~min}$ each, to remove any extractives (inorganic and organic non-structural components). Afterward, $750 \mathrm{~g}$ of the conditioned biomass materials were added to an in-house constructed 10 L Hastelloy C276 pressure reactor (Bozell et al., 2011) and loaded with $5.5 \mathrm{~kg}$ of water, such that the average solid loading was $14 \% \mathrm{w} / \mathrm{w}$. HWE was then conducted at $160^{\circ} \mathrm{C}$ for $60 \mathrm{~min}$, where the treatment duration was counted after the reactor reached the required temperature. The parameters for HWE were chosen based on our previous work (Wang et al., 2017). Post HWE, the reactor was cooled to $30^{\circ} \mathrm{C}$ and drained; all liquid hydrolysates were collected, filtered to remove any particulates, and then freeze-dried under reduced pressure $(0.2 \mathrm{mbar})$ at $-44^{\circ} \mathrm{C}$
(Labconco FreeZone 4.5 L system, Kansas City, MO). The freeze-dried product thus obtained was termed hemicellulosic oligosaccharides or "HOS." A schematic representation of HOS production is given in Figure 1. The HOS yield was calculated as follows:

$$
\text { HOS yield }(\%)=\frac{\text { Mass freezedried solids }(g)}{\text { Mass original biomass }(g)} \times 100
$$

\section{Chemical Characterization of HOS}

The monosaccharide composition of HOS was determined using a high-performance liquid chromatography (HPLC) system fitted with an Aminex HPX-87P analytical column (Bio-Rad Laboratories Inc., Hercules, CA) and a refractive index (RI) detector (Flexar, PerkinElmer, Waltham, MA). The column was maintained at $85^{\circ} \mathrm{C}$ with an eluent flow rate of rate of 0.25 $\mathrm{ml} / \mathrm{min}$. The system was calibrated using commercial sugar standards for xylose (Xyl), glucose (Glc), mannose (Man), arabinose, and galactose. The byproducts composition was measured using the same HPLC system (Flexar, PerkinElmer, Waltham, MA), but fitted with an Aminex HPX-87H analytical column and a photo diode array detector, calibrated using acetic acid, furfural, 5-hydroxymethylfurfural and formic acid standards purchased from Alfa-Aesar (Haverhill, MA).

The total oligosaccharide concentration was determined after digestion of the HOS with $4 \%(\mathrm{w} / \mathrm{w})$ sulfuric acid solution at $121^{\circ} \mathrm{C}$ for $1 \mathrm{~h}$; this process depolymerizes the oligosaccharides into monomeric sugars, which are then quantified using the same monosaccharide-detecting HPLC-RI method (Sluiter et al., 2008).

The total phenolic content of our HOS preparations was determined using the Folin-Ciocalteu method (Rajan and Carrier, 2016), where $200 \mu$ lof the $0.2 \mathrm{~N}$ phenol reagent (MP Biomedicals, Irvine, CA) was added to $100 \mu \mathrm{l}$ of $1.25 \mathrm{~g} / \mathrm{L}$ HOS and incubated in the dark for $5 \mathrm{~min}$. Afterward, $700 \mu \mathrm{l}$ of $7.5 \%$ sodium carbonate solution (Alfa-Aesar, Haverhill, MA) was added to the mixture and incubated in the dark at room temperature for $2 \mathrm{~h}$. For the instrument calibration, $100 \mu \mathrm{l}$ of gallic acid solution in 95\% methanol (Spectrum ${ }^{\mathrm{TM}}$, Gardena, CA) was used, at a concentration range of $0.04-0.2 \mathrm{~g} / \mathrm{L}$. A blank containing deionized water was also included. After $2 \mathrm{~h}$ of incubation, absorbances of the blank, calibration standards, as well as the HOS preparations were recorded at $765 \mathrm{~nm}$ using UV-Vis spectrophotometer (Lambda 650, PerkinElmer, Duluth, GA). The total phenolic content of HOS was expressed as gallic acid equivalent (i.e., g GAE/L).

TABLE 1 | Chemical composition of lignocellulosic biomass on extractives-free basis.

\begin{tabular}{|c|c|c|c|c|c|c|c|}
\hline \multirow[t]{2}{*}{ Feedstock } & \multicolumn{7}{|c|}{ Biomass composition (\% oven dry wt. basis)* } \\
\hline & Cellulose & Hemicellulose & $\begin{array}{c}\text { Acid insoluble } \\
\text { lignin }\end{array}$ & $\begin{array}{l}\text { Acid soluble } \\
\text { lignin" }^{\#}\end{array}$ & Acetyl & Ash & Mass closure \\
\hline Switchgrass (SG) & $40.0 \pm 1.6$ & $28.9 \pm 1.8$ & $15.3 \pm 0.3$ & $7.7 \pm 0.4$ & $4.8 \pm 0.2$ & $2.6 \pm 0.1$ & $99.3 \pm 2.6$ \\
\hline Hybrid poplar (HP) & $46.3 \pm 0.5$ & $23.6 \pm 0.5$ & $19.4 \pm 0.5$ & $6.4 \pm 0.1$ & $3.6 \pm 0.2$ & $1.1 \pm 0.0$ & $100.4 \pm 0.6$ \\
\hline Southern pine (SP) & $38.6 \pm 0.2$ & $21.9 \pm 0.1$ & $32.7 \pm 0.4$ & $2.5 \pm 0.1$ & $2.9 \pm 0.1$ & $0.5 \pm 0.0$ & $99.1 \pm 0.9$ \\
\hline
\end{tabular}

*Mean and SD provided for N = 3. Chemical composition was determined using National Renewable Energy Laboratory's (Golden, CO) standard protocols (Sluiter et al., 2010). "Acid soluble lignin content of SG was measured at $320 \mathrm{~nm}$, whereas for SP and HP at $240 \mathrm{~nm}$. 


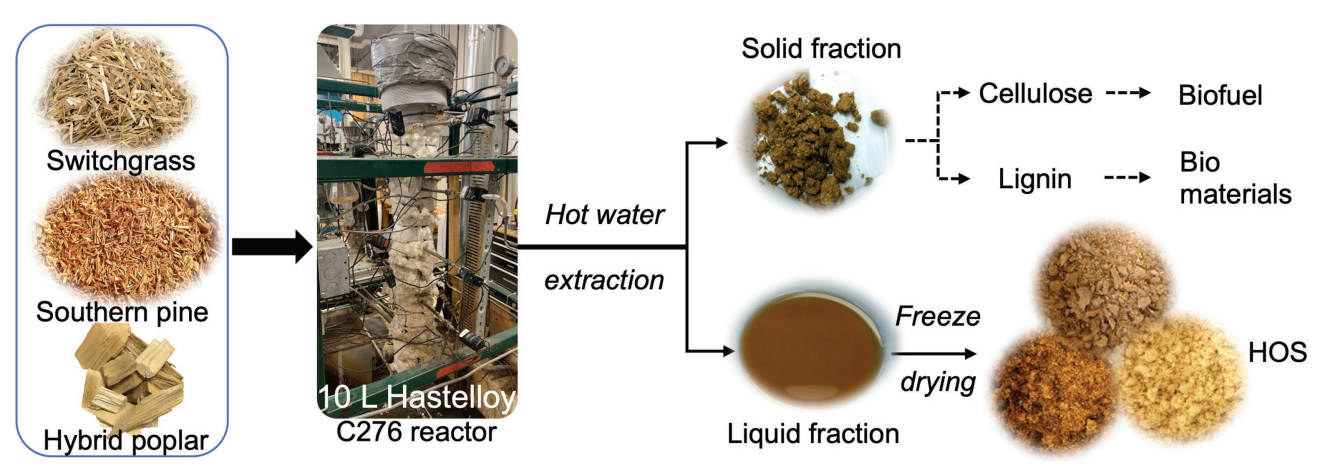

FIGURE 1 | Production scheme of hemicellulosic oligosaccharides (HOS) from switchgrass (SG), hybrid poplar (HP), and southern pine (SP) biomass, using hot water extraction (HWE) at $160^{\circ} \mathrm{C}$ for $60 \mathrm{~min}$. HOS is a co-product of biomass fractionation, and development of value-added prebiotic ingredients is a strategy for minimizing waste and increasing revenue in a biorefinery.

\section{Culturing Probiotic Bacterial Stocks}

Bifidobacterium bifidum (ATCC ${ }^{\otimes} 29521^{\mathrm{TM}}$ ) and Bacteroides fragilis (ATCC ${ }^{\circledR} 25285^{\mathrm{TM}}$ ), purchased from the American Type Culture Collection (Manassas, VA), were cultured in modified reinforced clostridial medium (ATCC ${ }^{\circledR}$ Medium \#2107) and modified chopped meat medium (ATCC ${ }^{\circledR}$ Medium \#1490), respectively. These bacteria were incubated in a static air-tight chamber, at $37^{\circ} \mathrm{C}$, that utilizes a GasPak ${ }^{\mathrm{TM}} \mathrm{EZ}$ pouch system (Becton, Dickinson \& Co., Sparks, MD) to generate anaerobic conditions. Lactobacillus casei was obtained from the culture collection of the Department of Food Science, the University of Tennessee Institute of Agriculture (Knoxville, TN), and grown in tryptic soy broth (TSB) medium at $37^{\circ} \mathrm{C}$ under aerobic conditions. The TSB medium was prepared using casein peptone $(17 \mathrm{~g} / \mathrm{L})$, sodium chloride $(5 \mathrm{~g} / \mathrm{L})$, soy peptone $(3 \mathrm{~g} / \mathrm{L})$, dextrose $(2.5 \mathrm{~g} / \mathrm{L})$, and dipotassium phosphate $(2.5 \mathrm{~g} / \mathrm{L})$ purchased from Alfa-Aesar (Haverhill, MA), where the $\mathrm{pH}$ was adjusted to 7.1. Isolated colonies were obtained and maintained on respective media.

\section{Prebiotic Activity Assays}

The in vitro fermentation assays were conducted using M9 minimal salts medium (Sigma-Aldrich, St. Louis, MO), which was prepared with $4 \mathrm{~g} / \mathrm{L}$ of carbon source, $2 \mathrm{mM} \mathrm{MgSO}_{4}$, $0.1 \mathrm{mM} \mathrm{CaCl}_{2}$, and adjusted to $\mathrm{pH}$ 7.1. Glucose, Xyl, or Man were used as controls for the carbon source, whereas the treatment groups contained $4 \mathrm{~g} / \mathrm{L}$ of switchgrass, hybrid poplar, or southern pine HOS. All media preparations were cold sterilized by passing through a $0.2 \mathrm{~mm}$ filter membrane under reduced pressure. Fresh stock cultures of all three probiotic bacteria having an average count of $1 \times 10^{11}$ cells $/ \mathrm{ml}$ were used as inoculum. Lactobacillus casei and B. fragilis were cultured in a high throughput assay, where $10 \mu \mathrm{l}$ of inocula were added to $200 \mu \mathrm{l}$ of modified M9 media in a 96-microwell plate and then incubated in a microplate reader (Synergy H1, BioTek Instruments, Burlington, VT) at $37^{\circ} \mathrm{C}$ for $120 \mathrm{~h}$. Bacterial growth was measured as optical density (OD) by the microplate reader every $30 \mathrm{~min}$ at $600 \mathrm{~nm}$. There were three biological replicates per bacterium per carbon source and each biological replicate had two technical replicates, totaling six replicates. A media blank was also included and $\mathrm{OD}_{600}$ readings taken at $0 \mathrm{~h}$ were used as the baseline to subtract from further measurements.

In the case of B. bifidum, which is not compatible for the high-throughput assay, $5 \mathrm{ml}$ media preparations taken in $\mathrm{N}_{2}$ flushed $10 \mathrm{ml}$ glass tubes were used. After adding $250 \mu \mathrm{l}$ of the prepared inoculum, these tubes were incubated at $37^{\circ} \mathrm{C}$ for $120 \mathrm{~h}$. Samples were manually collected every few hours and the $\mathrm{OD}_{600}$ was measured using the Synergy H1 microplate reader. These experiments were also repeated six times. Anaerobic conditions were induced for both B. fragilis and B. bifidum by sealing BD GasPak ${ }^{\mathrm{TM}} \mathrm{EZ}$ pouches inside the 96-well plates or the air-tight growth chambers. The $\mathrm{OD}_{600}$ readings were calibrated with bacterial cell counts obtained from a BD FACSAria III flow cytometer (Sparks, MD) fitted with a Sapphire 488-50 blue laser system (see Supplementary Figure S1). The prebiotic activity was generally expressed as total cell counts per $\mathrm{ml}$ of media. Batch fermentations on a $10 \mathrm{ml}$ scale were also performed in order to collect spent media every $24 \mathrm{~h}$ for further analyses.

\section{Chemical Characterization of Fermentation Media}

The composition of specific oligosaccharides contained in the HOS preparations (modified minimal salts media) was determined using a Dionex ${ }^{\mathrm{TM}}$ ICS-6000 high-performance anion exchange chromatography (HPAEC) system (Thermo Fisher Scientific, Madison, WI) fitted with a CarboPac ${ }^{\mathrm{TM}}$ PA200 analytical column $(250 \mathrm{~mm} \times 3 \mathrm{~mm})$ and a corresponding microbore guard column $(50 \mathrm{~mm} \times 3 \mathrm{~mm})$. The pulsed amperometric detection (PAD) system of ICS-6000 had a $\mathrm{AgCl}$ reference electrode and a gold working electrode. The mobile phases were composed of solvent A: $100 \mathrm{mM} \mathrm{NaOH}$, and solvent B: $100 \mathrm{mM} \mathrm{NaOH}$ mixed with $320 \mathrm{mM}$ sodium acetate. A gradient elution method was used as follows; hold $100 \%$ solvent $\mathrm{A}$ for $15 \mathrm{~min}$, then ramp to $50 \%$ solvent $\mathrm{B}$ at a linear rate for $40 \mathrm{~min}$, afterward increase solvent B to $100 \%$ in $1 \mathrm{~min}$ and hold constant for $4 \mathrm{~min}$; finally, return the mobile phase to $100 \%$ solvent $\mathrm{A}$ in $1 \mathrm{~min}$. The eluent flow rate was $0.5 \mathrm{ml} /$ min, injection volume was $10 \mu \mathrm{l}$, and the column temperature 
was $35^{\circ} \mathrm{C}$. Pure standards ( $\left.>95 \%\right)$ of cellobiose, xylobiose, xylotriose, xylotetraose, xylopentaose, xylohexaose, mannobiose, mannotriose, arabinobiose, and arabinotriose, purchased from Megazyme (Wicklow, Ireland), were used to calibrate the instrument.

\section{RESULTS AND DISCUSSION}

\section{Fractionation and Characterization of HOS}

Our previous work has shown that HWE procedure at $160^{\circ} \mathrm{C}$ for $60 \mathrm{~min}$ could be utilized to pretreat lignocellulosic biomass, namely hybrid poplar, switchgrass, and pine bark (Wang et al., 2017; Liu et al., 2018), to decrease inorganic impurities and reduce recalcitrance such that the overall biomass quality was enhanced for subsequent thermo- and biochemical conversion processes. The liquid hydrolysate obtained as a co-product during HWE is enriched in HOS, which could either be utilized for ethanol fermentation after extensive treatments (Phaiboonsilpa et al., 2020) or directly used for high-value applications such as prebiotics. In this work, we determined that HWE of SG, $\mathrm{HP}$, and SP biomass produced $11.9 \pm 0.2,10.8 \pm 0.2$, and $12.3 \pm 0.1 \%$ of $\mathrm{HOS}$ yields (Equation 1), respectively. The corresponding hemicellulose extraction efficiencies for SG, HP, and SP were $41.2 \pm 0.6,45.8 \pm 0.5$, and $56.2 \pm 0.2 \%$, respectively, based on the original biomass composition (Table 1). These efficiencies are similar to previously reported pilot scale hemicellulose extraction, at $50 \%$, from hardwood and softwood biomass using hot water (Kilpeläinen et al., 2014).

The monosaccharide and total oligosaccharide compositions of SG, HP, and SP-HOS are presented in Table 2. The predominant oligosaccharide in SG and HP-HOS was xylan, while in SP-HOS it was mannan, which is similar to other HOS preparations from herbaceous, softwood, and hardwood species. HOS isolated from Norway spruce, a softwood species with galactoglucomannan backbone, was composed of $53 \%$ mannan and that from Norway birch, a hardwood species with arabinoglucuronoxylan backbone, was composed of $82 \%$ xylan (La Rosa et al., 2019). In the case of herbaceous species, such as Miscanthus, the hot water hydrolysates were reported to contain 63\% xylan (Chen et al., 2015). Depending on their anatomical and chemical features, some feedstocks are more susceptible to hot water hydrolysis and hence, the corresponding HOS could depolymerize at an accelerated rate to form monosaccharides. The susceptibility of hemicellulosic backbone to autohydrolysis has been described as a function of degree of acetylation and the ratio of xylan to acid-insoluble lignin content (Lira, 2018). Accordingly, SG, which had comparatively higher number of acetyl groups as well as lower lignin content than HP (Table 1), produced higher amounts of monosaccharides during HWE. However, this was not the case when producing HOS from SP, which contained the highest concentration of monosaccharides at $184 \mathrm{~g} / \mathrm{L}$, despite the lower acetyl (2.9\%) and higher acidinsoluble lignin content $(32.7 \%)$ of SP biomass, indicating that further investigation is needed about glucomannan autohydrolysis kinetics.
TABLE 2 | Total saccharide composition of hemicellulosic hydrolysates fractionated from SG, HP, and SP biomass using hot water.

\begin{tabular}{|c|c|c|c|}
\hline Components (g/L)* & SG & HP & SP \\
\hline \multicolumn{4}{|c|}{ Monosaccharides (DP = 1$)$} \\
\hline Glucose & $3 \pm 0$ & - & $41 \pm 1$ \\
\hline Xylose & $36 \pm 1$ & $12 \pm 0$ & $49 \pm 2$ \\
\hline Galactose & - & $34 \pm 2$ & $25 \pm 0$ \\
\hline Arabinose & $47 \pm 5$ & $11 \pm 0$ & $27 \pm 0$ \\
\hline Mannose & - & - & $42 \pm 2$ \\
\hline \multicolumn{4}{|c|}{ Oligosaccharides (DP $\leq 6$ ) } \\
\hline Cellobiose & - & $40 \pm 2$ & $26 \pm 1$ \\
\hline Xylobiose & $21 \pm 1$ & $13 \pm 0$ & $38 \pm 2$ \\
\hline Xylotriose & $14 \pm 1$ & $3 \pm 0$ & $20 \pm 0$ \\
\hline Xylotetraose & $10 \pm 0$ & $3 \pm 0$ & $14 \pm 1$ \\
\hline Xylopentaose & $4 \pm 0$ & - & - \\
\hline Xylohexaose & $5 \pm 0$ & - & - \\
\hline Mannobiose & - & - & $28 \pm 1$ \\
\hline Mannotriose & - & - & $16 \pm 0$ \\
\hline Arabinobiose & $44 \pm 2$ & $21 \pm 1$ & $25 \pm 2$ \\
\hline Arabinotriose & $18 \pm 1$ & - & - \\
\hline \multicolumn{4}{|c|}{ Oligosaccharides (DP > 6)" } \\
\hline Glucan & $56 \pm 3$ & - & $94 \pm 2$ \\
\hline Xylan & $598 \pm 16$ & $664 \pm 14$ & $32 \pm 2$ \\
\hline Galactan & $74 \pm 6$ & $83 \pm 6$ & $106 \pm 3$ \\
\hline Arabinan & $36 \pm 3$ & $1 \pm 0$ & $10 \pm 0$ \\
\hline Mannan & $6 \pm 0$ & $77 \pm 2$ & $349 \pm 15$ \\
\hline
\end{tabular}

*Mean and $S D$ for $N=3$; $D P$, degree of polymerization.

"Quantified indirectly upon hydrolysis by 4\% sulfuric acid (S/uiter et al., 2008).

The HOS from SG, HP, and SP also contained degradation products of monosaccharides, formed under the high temperature and low pH conditions of HWE (Yan et al., 2016), namely acetic acid, formic acid, furfural, and 5-hydroxymethylfurfural. HP-HOS contained the lowest concentration of degradation products (Supplementary Table S1), whereas SP-HOS contained the highest concentration at $32 \mathrm{~g} / \mathrm{L}$, with formic acid $(13 \pm 1 \mathrm{~g} / \mathrm{L})$ and acetic acid $(10 \pm 1 \mathrm{~g} / \mathrm{L})$ sharing the majority. The total phenolic content, measured using the Folin-Ciocalteu method and expressed in gallic acid equivalent (GAE), was $10.3 \pm 1.0$, $7.4 \pm 0.1$, and $4.0 \pm 0.1 \mathrm{~g}$ GAE/L for SG, HP, and SP-HOS, respectively. Presence of phenolic compounds indicated that lignin was also partially depolymerized from the biomass materials during HWE (Yan et al., 2016). Despite the presence of carbohydrate and lignin degradation products, we tested the HOS directly without any purification. This approach could decrease costs as well as preserve the HOS yield rates.

\section{Selective Proliferation of Probiotic Bacteria in HOS}

We conducted in vitro fermentation studies with individual bacterial cultures of $L$. casei, B. bifidum, and B. fragilis in order to test the prebiotic potential of our SG-, HP-, and SP-HOS preparations. Xylose, glucose, and mannose sugars 
were used as control carbon sources in these tests. Previously, probiotic bacteria belonging to the genera of Lactobacillus and Bifidobacterium were successfully shown to proliferate in organosolv-pretreated cellulosic hydrolysates of birch and spruce wood (Karnaouri et al., 2019). Similarly, in vitro cultures of L. brevis, B. adolescentis, and B. catenulatum were reported to grow effectively in xylooligosaccharides fractionated using hot water from Miscanthus biomass (Chen et al., 2016; Hong et al., 2019). Moreover, in vivo studies have shown that bacteria belonging to Bacteroidaceae and Prevotellaceae could also assimilate xylooligosaccharides (Poeker et al., 2018). In our study, different probiotic bacteria grew at different rates in the HOS preparations.

As shown in Figure 2A, L. casei proliferated in all of the tested carbon sources, however, it displayed the highest cell counts in xylose and SG-HOS. Lactobacillus casei, being a facultative heterofermentative bacterium, has been previously reported to utilize a variety of carbon sources including xylose via the production of xylose isomerase and xylulose kinase enzymes (Chaillou et al., 1999). Specifically, strains with mutations affecting the phosphoenolpyruvate:mannose phosphotransferase system, have been reported to transport xylose via facilitated diffusion mechanism (Chaillou et al., 1999). Lactobacillus casei strains have also been reported to achieve a growth of $\leq 9$ $\log _{10}$ cells/ml in enzymatic hydrolysates of coffee peel (Ratnadewi et al., 2020), Napier grass and other herbaceous biomass (Patipong et al., 2019) that were enriched in xylooligosaccharides (degree of polymerization, DP $=2-5$ ). Therefore, the observed higher growth rates of $L$. casei could be attributed to its evolved tolerance in consuming xylose and xylooligosaccharides. Further investigation of L. casei's sugar consumption profiles is presented in the ensuing sections.

Bacteroides fragilis achieved higher growth rates in the controls, as well as in SP-HOS, when compared to the other hot water hydrolysates (Figure 2B). Bacteroides species have been reported to preferentially utilize pentoses at high dilutions and under carbon-limited conditions (Degnan and Macfarlane, 1995). It has been also shown that substrate specific transport systems can be readily induced in the Bacteroides species.
Bacteroides fragilis, specifically, has been reported to attain a cell density $\left(\mathrm{OD}_{600}\right)$ of 0.6 in autohydrolysates of spruce wood that were enriched in acetylated galactoglucomannan (La Rosa et al., 2019). In our study, B. fragilis attained a concentration of 5.8, 3.2, and $2.9 \log _{10}$ cells $/ \mathrm{ml}$, corresponding to $\mathrm{OD}_{600}$ of $0.32,0.25$, and 0.21 , in media containing SP-, SG-, and HP-HOS, respectively.

Bifidobacterium bifidum, on the other hand, exhibited significant growth in xylose and glucose controls, as well as in HP-HOS, when compared to other substrates (Figure 2C). Previous investigations have shown that carbon resource utilization by $B$. bifidum is strain dependent and most strains can utilize glucose, lactose, galactose, mannitol, and xylose, via inducible polyol dehydrogenase and fructokinase enzymes, and convert them into lactate and acetate (de Vries and Stouthamer, 1968). Other Bifidobacterium species have also been reported to utilize xylooligosaccharides $(\mathrm{DP}=3,4)$ isolated from the autohydrolysates of corn cob, achieving a $\mathrm{OD}_{600}$ of 0.7 (Moura et al., 2007). In our study, B. bifidum attained a growth rate of $6.4,4.8$, and $4.3 \log _{10}$ cells $/ \mathrm{ml}$, corresponding to $\mathrm{OD}_{600}$ of $0.37,0.30$, and 0.28 , in fermentation media containing HP-, SG-, and SP-HOS, respectively. Elucidation of fermentation media components utilized by B. bifidum would provide further insights about how this bacterium persevered in the test systems.

Overall, it is evident that our crude HOS preparations could support the growth of various probiotic bacteria even when containing carbohydrates and lignin degradation products. SG-HOS induced diauxic growth in L. casei, thereby maximizing carbon resource utilization and achieving cell populations similar to that of the xylose control. It is important to note that SG-HOS contained the highest concentration of phenolic compounds at $10.3 \mathrm{~g}$ GAE/L. SP-HOS induced moderate growth of $4-6 \log _{10}$ cells $/ \mathrm{ml}$ in all three probiotic bacteria, despite containing the highest concentration of carbohydrate degradation products at 32 g/L (Supplementary Table S1). HP-HOS induced the highest growth in B. bifidum, but relatively underperformed with other bacteria even though it contained the least concentration of degradation products (Supplementary Table S1). Thus, no trend was observed between the concentration of carbohydrate and

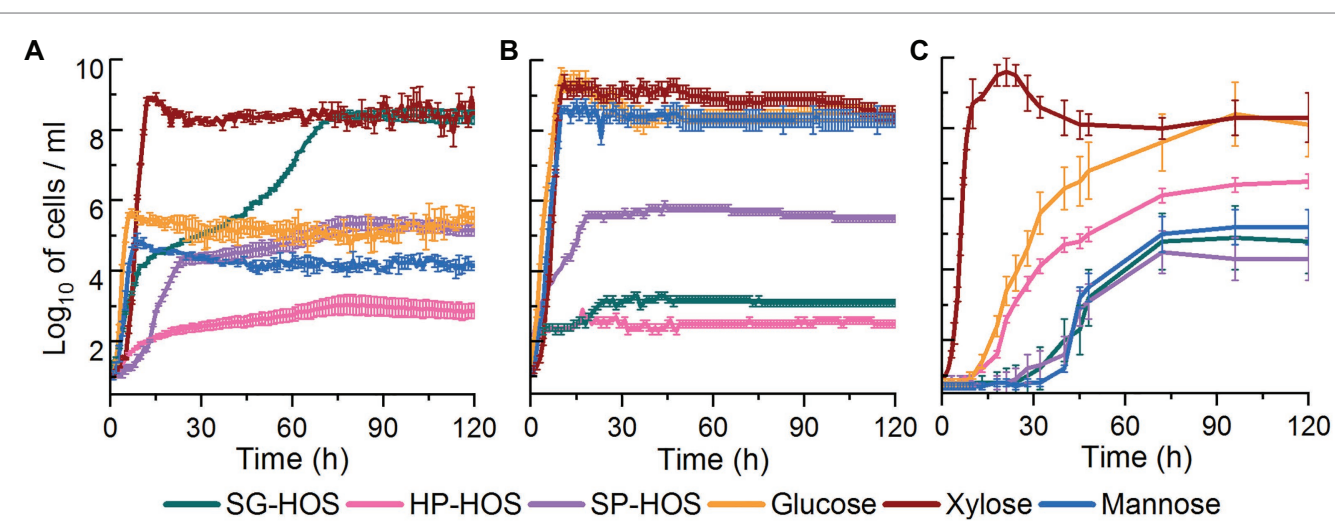

FIGURE 2 | Growth curves of (A) Lactobacillus casei, (B) Bacteroides fragilis, and (C) Bifidobacterium bifidum cultivated in media containing 4 g/L of HOS isolated from SG, HP, and SP. Pure glucose (Glc), xylose (Xyl), and mannose (Man) solutions at $4 \mathrm{~g} / \mathrm{L}$ were used as controls. Average cell counts and SDs are provided for $N=6$. Growth curves were constructed after subtracting the cell counts in the inoculum. 
lignin degradation products and that of the bacterial growth rates. Previous studies have shown that the presence of phenolic compounds like vanillic acid, gallic acid, flavonoids, and catechins, at 1-7 g/L, did not influence the viability of Lactobacillus spp. and B. bifidum (Gwiazdowska et al., 2015; Pacheco-Ordaz et al., 2017). Similarly, the presence of acetic acid (5-19 g/L), formic acid (5 g/L), furfural (1-4 g/L), and 5-hydroxymethylfurfural (1-5 g/L), was shown to actually enhance the substrate utilization and metabolite production in certain heterofermentative lactic acid bacteria like L. casei (Gubelt et al., 2020; Abdel-Rahman et al., 2021; Giacon et al., 2021). Hence, the observed differences in growth rates may be attributed to the differential assimilation of HOS sugars, instead of inhibition by the degradation products, and a detailed investigation of the spent media will reveal which of the available xylo-, manno-, gluco-, and arabinooligosaccharides in the SG-, HP-, and SP-HOS were utilized by L. casei, B. fragilis, and B. bifidum.

\section{Properties of HOS Affecting Probiotic Bacterial Growth}

\section{Effect of Monosaccharide Composition}

The analyses of the spent media after $120 \mathrm{~h}$ of fermentation by L. casei, B. fragilis, and B. bifidum by HPLC and HPAEC demonstrated that both mono- and oligo-saccharides in the HOS were utilized at different levels (Figures 3, 4). Lactobacillus casei utilized glucose and xylose to the fullest extent, both in the control as well as in our HOS preparations, but not mannose, which was consumed by only about $57 \%$ (Figure $3 \mathbf{A}$ ). The same manno-phosphotransferase transport system favoring xylose diffusion in L. casei should also enable mannose uptake; however, previous studies have reported similar discrepancies between xylose and mannose uptake (Das et al., 2019). It was revealed that, despite improved transport, mannose metabolism was affected due to the downregulation of specific (LSEI_0681) genes under nutrient restricted conditions (Licandro-Seraut et al., 2014). Hence, the nutrient restricted conditions of the minimal salt media must have affected the mannose metabolic pathway in $L$. casei in an adverse manner. In the case of SG-HOS, where glucose, xylose, and arabinose consumptions were upregulated, L. casei was able to establish sufficient growth during the first log phase as shown in Figure 2A. The chemical analysis of the spent media, as a function of time, also showed that all monomers in SG-HOS were consumed within 8-24 h (Supplementary Figure S2).

Bacteroides fragilis exhibited improved mannose consumption by 18 and $44 \%$ in the control when compared to L. casei and B. bifidum, respectively. It also exhibited improved co-consumption of mannose, xylose, and galactose sugars in HP- and SP-HOS (Figure 3B). Previous studies have shown that Bacteroides species can co-assimilate xylose, glucose, galactose and arabinose in the presence of mannose (Degnan and Macfarlane, 1995). Hence, SP-HOS, which contained the highest concentrations of mannose and other monosaccharides, elicited the fastest growth rate in $B$. fragilis.

Bifidobacterium bifidum exhibited a longer lag phase than other probiotic bacteria, even in the glucose control, possibly due to the low concentration of carbon sources at only $4 \mathrm{~g} / \mathrm{L}$ (Figure 2C). Although this bacterium originally evolved to metabolize galactooligosaccharides, previous studies have found genes encoding transporter and metabolic systems in different $B$. bifidum strains that enabled glucose, xylose and fructose utilization (Turroni et al., 2012). In our study, HP-HOS, which had the highest galactose concentration, promoted early B. bifidum establishment and reduced the lag time when compared to SG- or SP-HOS (Figure 2C). Even though this strain utilized different monosaccharides, including xylose, mannose and arabinose in different hydrolysates (Figure 3C), presence of galactose seemed to be crucial for achieving higher cell counts.

\section{Effect of Oligosaccharide Composition}

The tested probiotic bacteria also consumed oligosaccharides present in the hemicellulosic hydrolysates, as shown in Figure 4.

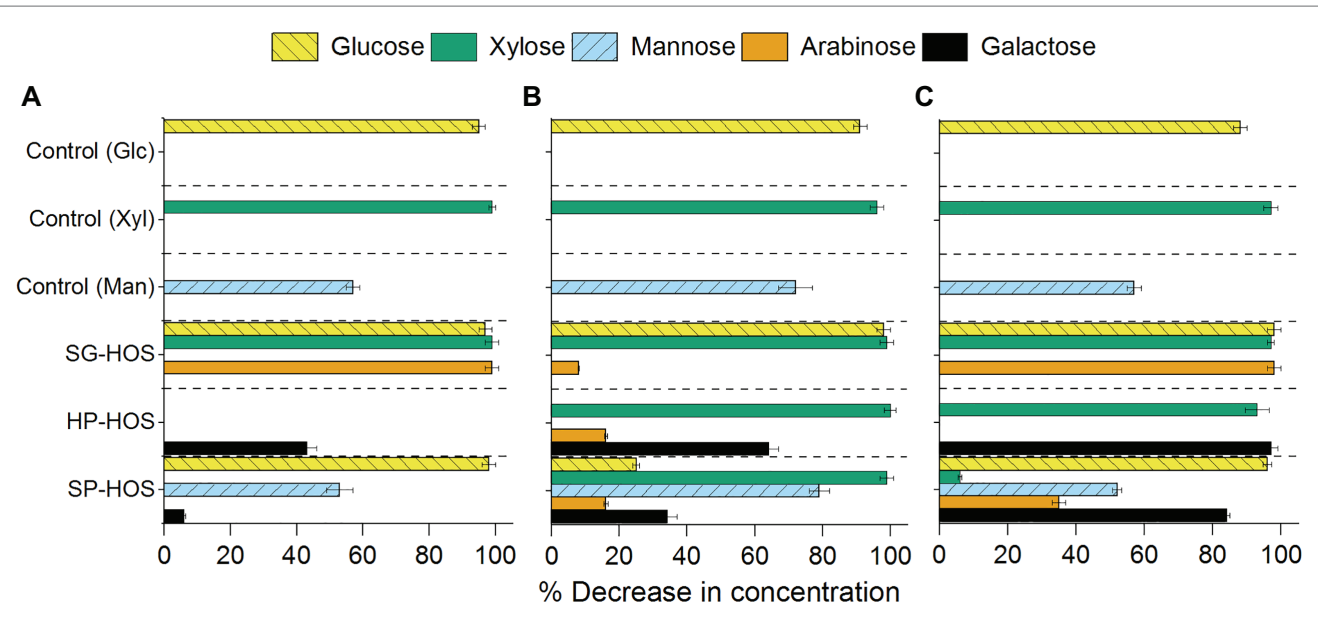

FIGURE 3 | Monosaccharides consumed (in spent media) after 120 h of fermentation by (A) L. casei, (B) B. fragilis, and (C) B. bifidum. Average monomeric sugar utilization in the SG, HP, and SP HOS was determined by high-performance liquid chromatography (HPLC). Glucose, Xyl, and Man sugars were used as control carbon sources in the fermentation media. Error bars represent standard deviations for $N=3$. 


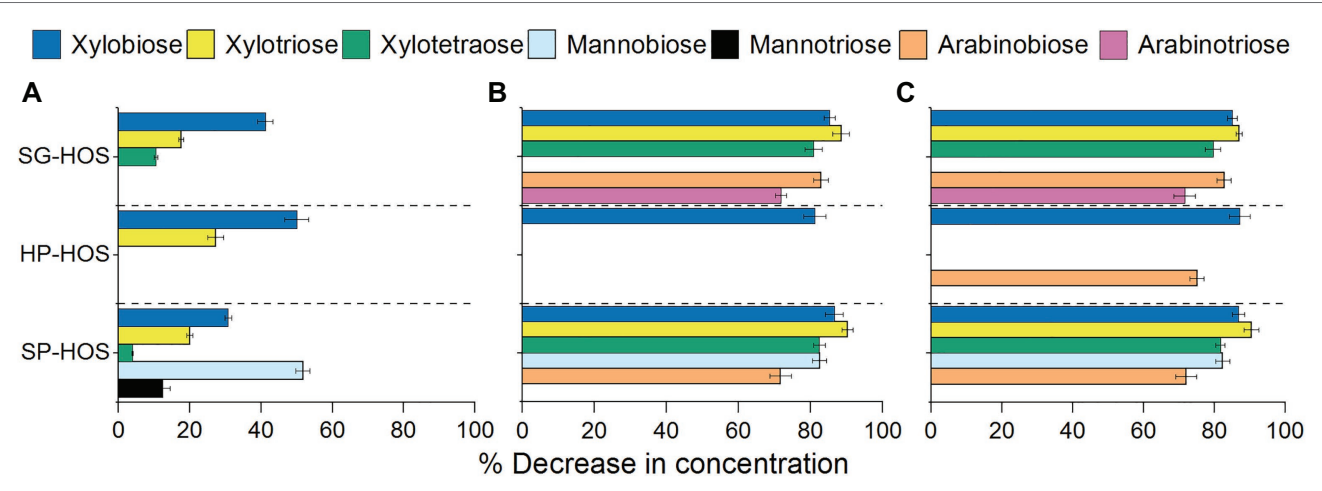

FIGURE 4 | Characterization of oligosaccharides in the spent media after $120 \mathrm{~h}$ of fermentation by (A) L. casei, (B) B. fragilis, and (C) B. bifidum. Average sugar composition of media containing SG, HP, and SP HOS was determined using high-performance anion exchange chromatography (HPAEC)-pulsed amperometric detection (PAD) analysis. Error bars represent SDs for $N=3$.

Lactobacillus casei utilized the lowest amount and variety of oligosaccharides (Figure 4A), exhibiting preference towards xylooligosaccharides (DP $=2-4$ ). In SG-HOS, utilization of xylobiose and xylotriose between 48 and $72 \mathrm{~h}$ of fermentation (Supplementary Figure S2) induced the second log phase in L. casei, thereby attaining higher cell counts. At approximately $60 \mathrm{~h}$ of growth, L. casei also hydrolyzed mannobiose and mannotriose in SP-HOS, leading to an increase in mannose concentration in the media (Supplementary Figure S2); however, since mannose was not a preferred carbon source, L. casei's growth rate did not reach the potential maxima (Figure 2A). Xylobiose and xylotriose in HP-HOS were not metabolized until after $72 \mathrm{~h}$ by $L$. casei, and hence was not sufficient to promote its proliferation.

Bacteroides fragilis fermentation led to the reduction in concentrations of xylo-, manno-, and arabinooligosaccharides (DP = 2-4) measured in the HOS media preparations (Figure 4B). However, the corresponding growth rates in HPand SG-HOS were lacking. This could be because, while $B$. fragilis has the transport mechanism, necessary enzymes (mannobiose 2-epimerase, mannosylglucose phosphorylase) and regulatory system to metabolize mannobiose (Kawaguchi et al., 2014), it may not have the metabolic or regulatory pathways to assimilate xylo- or arabinooligosaccharides (La Rosa et al., 2019). Hence, B. fragilis proliferated markedly in SP-HOS, which contained the highest concentrations of mannooligosaccharides when compared to HP and SG-HOS (Table 2).

Similarly, in B. bifidum, despite the reduction in concentrations of several available oligosaccharides in all HOS preparations (Figure 4C), only HP-HOS promoted the highest growth rates. Previous research has shown that several Bifidobacterium strains possessed the putative genes for expressing extracellular $\beta$-endoxylanase and $\beta$-xylosidase as well as $\alpha$-arabinofuranosidase, conducive to hydrolyze complex arabinoxylan backbones (Rivière et al., 2014). Hence, the observed reduction in xylo- and arabino-oligosaccharide concentration in B. bifidum spent media may be attributed to their depolymerization into xylose and arabinose, as facilitated by the extracellular enzymes. Accordingly, the fermentation media at $120 \mathrm{~h}$ displayed an increase in xylose concentration by 1 and 35\% in HP-HOS and SG-HOS, respectively
(Supplementary Figure S4). Fermented SP-HOS media, after $120 \mathrm{~h}$, also showed an increase in arabinose, glucose, and mannose concentrations by 9,13 , and $14 \%$, respectively. This illustrates that $B$. bifidum may also have genes encoding extracellular $\beta$-mannosidases and other glucomannan degrading enzymes, although additional work is needed to substantiate this hypothesis. Overall, it could be concluded that B. bifidum was more efficient in degrading and utilizing complex HP-HOS, since only 1 and $2 \%$ of excess xylose and galactose, respectively, were detected in the spent media at $120 \mathrm{~h}$ (Supplementary Figure S4). On the other hand, B. bifidum exhibited prolonged lag phase in SG- and SP-HOS preparations and hence, the subsequent depolymerization and utilization of complex HOS sugars was delayed leading to comparatively lower cell counts.

It is of note that the higher-order oligosaccharides (DP > 4), which were not depleted in the fermentation media, could still impart beneficial functions when utilized as prebiotic ingredients. Studies have shown that large molecular weight oligosaccharides could improve bowel movement, gut barrier functions, anti-pathogenic activity as well as enhance the immune response in mammalian model systems (Pourabedin and Zhao, 2015; Pham et al., 2018). Alternatively, the hot water extraction conditions could be optimized to directly yield lower order HOS (DP = 2-4; Jang et al., 2021) or an additional enzymatic hydrolysis step, using endo- $\beta$-xylanase and endo- $\beta$-mannanase, could be included in order to convert the HOS into lower molecular weight ( $\mathrm{DP}=2,3$ ) oligosaccharides (Huang et al., 2019). Overall, the HOS substrates demonstrated in this study have immense potential for further clinical studies and exploration of bacterial assimilation mechanisms.

\section{CONCLUSION}

From this study, we can conclude that, hemicellulosic hydrolysates isolated using industrially relevant hot water extraction process from dedicated bioenergy crops such as switchgrass, and hybrid poplar and from southern pine could serve as prebiotic substrates. Switchgrass HOS induced a diauxic growth pattern in L. casei 
and also resulted in the highest cell count amidst all tested probiotic bacteria and HOS substrates. In the case of hybrid poplar HOS, the initial availability of galactose led to a shorter lag phase in B. bifidum, whose growth rate was then sustained via the consumption of extracellularly depolymerized arabinoand xylooligosaccharides. This suggests that the initial establishment of probiotic bacteria and subsequent sustenance through oligosaccharide assimilation is essential to promote probiotic activity. We also observed that $B$. fragilis proliferated in southern pine HOS, exhibiting the capability to assimilate mannooligosaccharides. Although some of the underlying transport and metabolization mechanisms have been elucidated for Lactobacillus, Bifidobacteria, and Bacteroides species with respect to xylooligosaccharides consumption, we propose to further investigate the gene expressions specifically promoting the utilization of SG-, HP-, and SP-HOS in our future work. Overall, this study provides a promising outlook for developing high-value prebiotics from biorefinery-relevant feedstocks.

\section{DATA AVAILABILITY STATEMENT}

The original contributions presented in the study are included in the article/Supplementary Material, further inquiries can be directed to the corresponding authors.

\section{AUTHOR CONTRIBUTIONS}

KR conducted the experiments in conjunction with co-authors $\mathrm{KK}$ and JC. KR and KK also did the data analysis. NL led the conception of this study and was instrumental for the

\section{REFERENCES}

Abdel-Rahman, M. A., Hassan, S. E.-D., Fouda, A., Radwan, A. A., Barghoth, M. G., and Desouky, S. G. (2021). Evaluating the effect of lignocellulose-derived microbial inhibitors on the growth and lactic acid production by Bacillus coagulans Azu-10. Fermentation 7:17. doi: 10.3390/fermentation7010017

Ahuja, K., and Deb, S. (2017). "Prebiotics market size by ingredient, by application, dietary supplements, industry analysis report, regional outlook, application potential, price trends, competitive market share \& forecast, 2017-2024", in Food, Nutrition and Animal Feed. Selbyville, DE.

Baral, N. R., Davis, R., and Bradley, T. H. (2019). Supply and value chain analysis of mixed biomass feedstock supply system for lignocellulosic sugar production. Biofuels Bioprod. Biorefin. 13, 635-659. doi: 10.1002/bbb.1975

Bozell, J. J., Black, S. K., Myers, M., Cahill, D., Miller, W. P., and Park, S. (2011). Solvent fractionation of renewable woody feedstocks: organosolv generation of biorefinery process streams for the production of biobased chemicals. Biomass Bioenergy 35, 4197-4208. doi: 10.1016/j.biombioe.2011.07.006

Chaillou, S., Pouwels, P. H., and Postma, P. W. (1999). Transport of D-xylose in Lactobacillus pentosus, Lactobacillus casei, and Lactobacillus plantarum: evidence for a mechanism of facilitated diffusion via the phosphoenolpyruvate:mannose phosphotransferase system. J. Bacteriol. 181, 4768-4773. doi: 10.1128/JB.181.16.4768-4773.1999

Chen, M.-H., Bowman, M. J., Cotta, M. A., Dien, B. S., Iten, L. B., Whitehead, T. R., et al. (2016). Miscanthus $\times$ giganteus xylooligosaccharides: purification and fermentation. Carbohydr. Polym. 140, 96-103. doi: 10.1016/j.carbpol.2015.12.052

Chen, M.-H., Rajan, K., Carrier, D. J., and Singh, V. (2015). Separation of xylose oligomers from autohydrolyzed Miscanthus $\mathrm{x}$ giganteus using centrifugal study design along with DD'S, KR, and DC. KR in conjunction with NL, DD'S, TE, and DC prepared and edited this manuscript. All authors contributed to the article and approved the submitted version.

\section{FUNDING}

This research was partly funded by the US Forest Service (Award \#19-JV-5941130131-026) and by the USDA National Institute of Food and Agriculture (Award \#2018-67009-27375). This work was also supported by the USDA-NIFA, Hatch project \#1012359.

\section{ACKNOWLEDGMENTS}

We thank Tingting $\mathrm{Xu}$, at the University of Tennessee - Center for Environmental Biology's core facilities, for conducting the flow cytometry experiments. We also thank Alex Bowman, graduate student in the University of Tennessee's College of Veterinary Medicine, for helping with the bacterial fermentations. Finally, we acknowledge the partial support provided by the Equipment and Infrastructure Program of the University of Tennessee - Scholarly Activity and Research Incentive Fund, which was used to purchase the HPAEC-PAD system.

\section{SUPPLEMENTARY MATERIAL}

The Supplementary Material for this article can be found online at: https://www.frontiersin.org/articles/10.3389/fmicb.2021.6753 14/full\#supplementary-material

partition chromatography. Food Bioprod. Process. 95, 125-132. doi: 10.1016/j. fbp.2015.04.006

Das, A. J., Das, M. J., Miyaji, T., and Deka, S. C. (2019). Growth and metabolic characterization of four lactic acid bacteria species isolated from rice beer prepared in Assam, India. Access Microbiol. 1:e000028. doi: 10.1099/ acmi.0.000028

Davani-Davari, D., Negahdaripour, M., Karimzadeh, I., Seifan, M., Mohkam, M., Masoumi, S. J., et al. (2019). Prebiotics: definition, types, sources, mechanisms, and clinical applications. Foods 8:92. doi: 10.3390/foods8030092

Degnan, B. A., and Macfarlane, G. T. (1995). Carbohydrate utilization patterns and substrate preferences in Bacteroides thetaiotaomicron. Anaerobe 1, 25-33. doi: 10.1016/s1075-9964(95)80392-0

de Vries, W., and Stouthamer, A. H. (1968). Fermentation of glucose, lactose, galactose, mannitol, and xylose by Bifidobacteria. J. Bacteriol. 96, 472-478. doi: $10.1128 /$ JB.96.2.472-478.1968

Edmunds, C. W., Molina, E. A. R., André, N., Hamilton, C., Park, S., Fasina, O., et al. (2018). Blended feedstocks for thermochemical conversion: biomass characterization and bio-oil production from switchgrass-pine residues blends. Front. Energy Res. 6:79. doi: 10.3389/fenrg.2018.00079

Gallina, G., Cabeza, Á., Grénman, H., Biasi, P., García-Serna, J., and Salmi, T. (2018). Hemicellulose extraction by hot pressurized water pretreatment at $160^{\circ} \mathrm{C}$ for 10 different woods: yield and molecular weight. J. Supercrit. Fluids 133, 716-725. doi: 10.1016/j.supflu.2017.10.001

Geng, W., Venditti, R. A., Pawlak, J. J., and Chang, H.-M. (2018). Effect of delignification on hemicellulose extraction from switchgrass, poplar, and pine and its effect on enzymatic convertibility of cellulose-rich residues. Bioresources 13, 4946-4963. doi: 10.15376/biores.13.3.4946-4963 
Giacon, T. G., Cunha, G. C. D. G., Eliodório, K. P., de Souza Oliveira, P., and Basso, T. O. (2021). Homo-and heterofermentative lactobacilli are differently affected by lignocellulosic inhibitory compounds. bioRxiv 1:23. [Preprint]. doi: 10.1101/2021.01.18.427060

Gray, J. A., Bentley, J. W., Cooper, J. A., and Wall, D. J. (2018). "Southern pulpwood production, 2015". Asheville, NC: U.S. Department of Agriculture Forest Service, Southern Research Station, 1-15.

Gubelt, A., Blaschke, L., Hahn, T., Rupp, S., Hirth, T., and Zibek, S. (2020). Comparison of different lactobacilli regarding substrate utilization and their tolerance towards lignocellulose degradation products. Curr. Microbiol. 77, 3136-3146. doi: 10.1007/s00284-020-02131-y

Gwiazdowska, D., Juś, K., Jasnowska-Małecka, J., and Kluczyńska, K. (2015). The impact of polyphenols on Bifidobacterium growth. Acta Biochim. Pol. 62, 895-901. doi: 10.18388/abp.2015_1154

Hansen, C. H., Frøkiær, H., Christensen, A. G., Bergström, A., Licht, T. R., Hansen, A. K., et al. (2013). Dietary xylooligosaccharide downregulates IFN- $\gamma$ and the low-grade inflammatory cytokine IL-1 $\beta$ systemically in mice. J. Nutr. 143, 533-540. doi: 10.3945/jn.112.172361

Hill, D., Sugrue, I., Tobin, C., Hill, C., Stanton, C., and Ross, R. P. (2018). The Lactobacillus casei group: history and health related applications. Front. Microbiol. 9:2107. doi: 10.3389/fmicb.2018.02107

Hong, C. Y., Corbett, D., Venditti, R., Jameel, H., and Park, S. (2019). Xylooligosaccharides as prebiotics from biomass autohydrolyzate. LWT 111, 703-710. doi: 10.1016/j.lwt.2019.05.098

Hsu, C. K., Liao, J. W., Chung, Y. C., Hsieh, C. P., and Chan, Y. C. (2004). Xylooligosaccharides and fructooligosaccharides affect the intestinal microbiota and precancerous colonic lesion development in rats. J. Nutr. 134, 1523-1528. doi: $10.1093 /$ jn/134.6.1523

Huang, C., Wang, X., Liang, C., Jiang, X., Yang, G., Xu, J., et al. (2019). A sustainable process for procuring biologically active fractions of high-purity xylooligosaccharides and water-soluble lignin from Moso bamboo prehydrolyzate. Biotechnol. Biofuels 12:189. doi: 10.1186/s13068-019-1527-3

Jang, S.-K., Kim, J.-H., Choi, J.-H., Cho, S.-M., Kim, J.-C., Kim, H., et al. (2021). Evaluation of xylooligosaccharides production for a specific degree of polymerization by liquid hot water treatment of tropical hardwood. Foods 10:463. doi: 10.3390/foods10020463

Karnaouri, A., Matsakas, L., Krikigianni, E., Rova, U., and Christakopoulos, P. (2019). Valorization of waste forest biomass toward the production of cellooligosaccharides with potential prebiotic activity by utilizing customized enzyme cocktails. Biotechnol. Biofuels 12:285. doi: 10.1186/s13068-019-1628-Z

Kawaguchi, K., Senoura, T., Ito, S., Taira, T., Ito, H., Wasaki, J., et al. (2014). The mannobiose-forming exo-mannanase involved in a new mannan catabolic pathway in Bacteroides fragilis. Arch. Microbiol. 196, 17-23. doi: 10.1007/ s00203-013-0938-y

Kilpeläinen, P. O., Hautala, S. S., Byman, O. O., Tanner, L. J., Korpinen, R. I., Lillandt, M. K.-J., et al. (2014). Pressurized hot water flow-through extraction system scale up from the laboratory to the pilot scale. Green Chem. 16, 3186-3194. doi: 10.1039/C4GC00274A

Kim, Y., Hendrickson, R., Mosier, N. S., and Ladisch, M. R. (2009). "Liquid hot water pretreatment of cellulosic biomass" in Biofuels: Methods in Molecular Biology. ed. J. Mielenz (Totowa, NJ: Humana Press), 93-102.

Kim, S., Kim, S., Cho, J., Park, S., Perez, F. X. J., and Kiniry, J. R. (2020). Simulated biomass, climate change impacts, and $\mathrm{n}$ itrogen management to achieve switchgrass biofuel production at diverse sites in U.S. Agronomy 10:503. doi: 10.3390/agronomy 10040503

Krogell, J., Korotkova, E., Eränen, K., Pranovich, A., Salmi, T., Murzin, D., et al. (2013). Intensification of hemicellulose hot-water extraction from spruce wood in a batch extractor-effects of wood particle size. Bioresour. Technol. 143, 212-220. doi: 10.1016/j.biortech.2013.05.110

La Rosa, S. L., Kachrimanidou, V., Buffetto, F., Pope, P. B., Pudlo, N. A., Martens, E. C., et al. (2019). Wood-derived dietary fibers promote beneficial human gut microbiota. mSphere 4, e00554-e00618. doi: 10.1128/ mSphere.00554-18

Licandro-Seraut, H., Scornec, H., Pédron, T., Cavin, J.-F., and Sansonetti, P. J. (2014). Functional genomics of Lactobacillus casei establishment in the gut. Proc. Natl. Acad. Sci. U. S. A. 111, E3101-E3109. doi: 10.1073/pnas.1411883111

Lira, C. (2018). Autohydrolysis pretreatment of mixed lignocellulosic biomass. Doctor of Philosophy. Ontario, Canada: The University of Western Ontario, 142 .
Liu, Q., Labbé, N., Adhikari, S., Chmely, S. C., and Abdoulmoumine, N. (2018). Hot water extraction as a pretreatment for reducing syngas inorganics impurities-A parametric investigation on switchgrass and loblolly pine bark. Fuel 220, 177-184. doi: 10.1016/j.fuel.2018.01.108

Lolou, V., and Panayiotidis, M. I. (2019). Functional role of probiotics and prebiotics on skin health and disease. Fermentation 5:41. doi: 10.3390/ fermentation5020041

Moura, P., Barata, R., Carvalheiro, F., Gírio, F., Loureiro-Dias, M. C., and Esteves, M. P. (2007). In vitro fermentation of xylo-oligosaccharides from corn cobs autohydrolysis by Bifidobacterium and Lactobacillus strains. LWT Food Sci. Technol. 40, 963-972. doi: 10.1016/j.lwt.2006.07.013

Ng, S. Y., Chia, L. W., Padam, B. S., and Chye, F. Y. (2014). Effect of selected oligosaccharides on the viability and fermentation kinetics of Lactobacillus acidophilus and Lactobacillus casei in cultured milk. J. Pharm. Nutr. Sci. 4, 92-99. doi: 10.6000/1927-5951.2014.04.02.4

Pacheco-Ordaz, R., Wall-Medrano, A., Goni, M. G., Ramos-Clamont-Montfort, G., AyalaZavala, J. F., and Gonzalez-Aguilar, G. A. (2017). Effect of phenolic compounds on the growth of selected probiotic and pathogenic bacteria. Lett. Appl. Microbiol. 66, 25-31. doi: 10.1111/lam.12814

Patipong, T., Lotrakul, P., Padungros, P., Punnapayak, H., Bankeeree, W., and Prasongsuk, S. (2019). Enzymatic hydrolysis of tropical weed xylans using xylanase from Aureobasidium melanogenum PBUAP46 for xylooligosaccharide production. 3 Biotech 9:56. doi: 10.1007/s13205-019-1586-y

Phaiboonsilpa, N., Chysirichote, T., Champreda, V., and Laosiripojana, N. (2020). Fermentation of xylose, arabinose, glucose, their mixtures and sugarcane bagasse hydrolyzate by yeast Pichia stipitis for ethanol production. Energy Rep. 6, 710-713. doi: 10.1016/j.egyr.2019.11.142

Pham, V. T., Seifert, N., Richard, N., Raederstorff, D., Steinert, R., Prudence, K., et al. (2018). The effects of fermentation products of prebiotic fibres on gut barrier and immune functions in vitro. PeerJ 6:e5288. doi: 10.7717/ peerj. 5288

Poeker, S. A., Geirnaert, A., Berchtold, L., Greppi, A., Krych, L., Steinert, R. E., et al. (2018). Understanding the prebiotic potential of different dietary fibers using an in vitro continuous adult fermentation model (PolyFermS). Sci. Rep. 8:4318. doi: 10.1038/s41598-018-22438-y

Pourabedin, M., and Zhao, X. (2015). Prebiotics and gut microbiota in chickens. FEMS Microbiol. Lett. 362:122. doi: 10.1093/femsle/fnv122

Rajan, K., and Carrier, D. J. (2016). Insights into exo-cellulase inhibition by the hot water hydrolyzates of rice straw. ACS Sustain. Chem. Eng. 4, 3627-3633. doi: 10.1021/acssuschemeng.5b01778

Ratnadewi, A. A. I., Zain, M. H. A., Kusuma, A. A. N. N., Handayani, W., Nugraha, A. S., and Siswoyo, T. A. (2020). Lactobacillus casei fermentation towards xylooligosaccharide (XOS) obtained from coffee peel enzymatic hydrolysate. Biocatal. Agric. Biotechnol. 23:101446. doi: 10.1016/j. bcab.2019.101446

Rivière, A., Moens, F., Selak, M., Maes, D., Weckx, S., and De Vuyst, L. (2014). The ability of Bifidobacteria to degrade arabinoxylan oligosaccharide constituents and derived oligosaccharides is strain dependent. Appl. Environ. Microbiol. 80, 204-217. doi: 10.1128/AEM.02853-13

Rusanen, A., Lappalainen, K., Kärkkäinen, J., Tuuttila, T., Mikola, M., and Lassi, U. (2019). Selective hemicellulose hydrolysis of scots pine sawdust. Biomass Convers. Biorefin. 9, 283-291. doi: 10.1007/s13399-0180357-z

Sims, I. M., and Tannock, G. W. (2020). Galacto- and fructo-oligosaccharides utilized for growth by cocultures of bifidobacterial species characteristic of the infant gut. Appl. Environ. Microbiol. 86, e00214-e00220. doi: 10.1128/ AEM.00214-20

Sluiter, A., Hames, B., Ruiz, R., Scarlata, C., Sluiter, J., and Templeton, D. (2008). "Determination of sugars, byproducts, and degradation products in liquid fraction process samples" in Laboratory Analytical Procedure. (Golden, Colorado: National Renewable Energy Laboratory), 1-14.

Sluiter, J. B., Ruiz, R. O., Scarlata, C. J., Sluiter, A. D., and Templeton, D. W. (2010). Compositional analysis of lignocellulosic feedstocks. 1. Review and description of methods. J. Agric. Food Chem. 58, 9043-9053. doi: 10.1021/ jf1008023

Spiridon, I., and Popa, V. I. (2008). "Hemicelluloses: major sources, properties and applications" in Monomers, Polymers and Composites From Renewable Resources. eds. M. N. Belgacem and A. Gandini (Amsterdam, Netherlands: Elsevier), 289-304. 
Takkellapati, S., Li, T., and Gonzalez, M. A. (2018). An overview of biorefinery derived platform chemicals from a cellulose and hemicellulose biorefinery. Clean Technol. Environ. Policy 20, 1615-1630. doi: 10.1007/s10098-018-1568-5

Thiennimitr, P., Yasom, S., Tunapong, W., Chunchai, T., Wanchai, K., Pongchaidecha, A., et al. (2018). Lactobacillus paracasei HII01, xylooligosaccharides, and synbiotics reduce gut disturbance in obese rats. Nutrition 54, 40-47. doi: 10.1016/j.nut.2018.03.005

Townsend, P. A., Haider, N., Boby, L., Heavey, J., Miller, T. A., and Volk, T. A. (2018). "A roadmap for polar and willow to provide environmental services to build the bioeconomy" in Environmental Applications. eds. N. Hart, J. Isebrands, C. Johnston, L. Licht, M. Shell, B. Simmons, et al. (Pullman, WA: Washington State University), 1-36.

Turroni, F., Milani, C., Duranti, S., Lugli, G. A., Bernasconi, S., Margolles, A., et al. (2020). The infant gut microbiome as a microbial organ influencing host well-being. Ital. J. Pediatr. 46:16. doi: 10.1186/s13052-020-0781-0

Turroni, F., Strati, F., Foroni, E., Serafini, F., Duranti, S., Van Sinderen, D., et al. (2012). Analysis of predicted carbohydrate transport systems encoded by Bifidobacterium bifidum PRL2010. Appl. Environ. Microbiol. 78, 5002-5012. doi: 10.1128/AEM.00629-12

Volk, T. A., Berguson, B., Daly, C., Halbleib, M., Miller, R., Rials, T., et al. (2018). Poplar and shrub willow energy crops in the United States: field trial results from the multiyear regional feedstock partnership and yield potential maps based on the PRISM-ELM model. GCB Bioenergy 10, 735-751. doi: 10.1111/gcbb.12498

Wang, J., Boy, R., Nguyen, N. A., Keum, J. K., Cullen, D. A., Chen, J., et al. (2017). Controlled assembly of lignocellulosic biomass components and properties of reformed materials. ACS Sustain. Chem. Eng. 5, 8044-8052. doi: 10.1021/acssuschemeng.7b01639
Wells, J. M., Drielak, E., Surendra, K. C., and Khanal, S. K. (2020). Hot water pretreatment of lignocellulosic biomass: modeling the effects of temperature, enzyme and biomass loadings on sugar yield. Bioresour. Technol. 300:122593. doi: 10.1016/j.biortech.2019.122593

Yadav, M., Paritosh, K., Chawade, A., Pareek, N., and Vivekanand, V. (2018). Genetic engineering of energy crops to reduce recalcitrance and enhance biomass digestibility. Agriculture 8:76. doi: 10.3390/agriculture 8060076

Yan, L., Ma, R., Li, L., and Fu, J. (2016). Hot water pretreatment of lignocellulosic biomass: an effective and environmentally friendly approach to enhance biofuel production. Chem. Eng. Techol. 39, 1759-1770. doi: 10.1002/ ceat. 201600394

Yang, J., Summanen, P. H., Henning, S. M., Hsu, M., Lam, H., Huang, J., et al. (2015). Xylooligosaccharide supplementation alters gut bacteria in both healthy and prediabetic adults: a pilot study. Front. Physiol. 6:216. doi: 10.3389/fphys.2015.00216

Conflict of Interest: The authors declare that the research was conducted in the absence of any commercial or financial relationships that could be construed as a potential conflict of interest.

Copyright (C) 2021 Rajan, D’Souza, Kim, Choi, Elder, Carrier and Labbé. This is an open-access article distributed under the terms of the Creative Commons Attribution License (CC BY). The use, distribution or reproduction in other forums is permitted, provided the original author(s) and the copyright owner(s) are credited and that the original publication in this journal is cited, in accordance with accepted academic practice. No use, distribution or reproduction is permitted which does not comply with these terms. 